\title{
El lugar del acompañamiento psicológico en el proceso de formación en el Seminario Mayor
}

DOI: https://doi.org/10.52039/seminarios.v54i189-190.528

\section{INTRODUCCIÓN}

Hace unos días, exactamente el 30 el Octubre, la Congregación para la Educación católica (CEC), publicó un Documento: Orientaciones para el uso de las competencias de la psicología en la admisión y en la formación de los candidatos al sacerdocio.

Este era más o menos el tema de la comunicación que se me pidió, por eso voy a aludir a ella, e intentaré aportar algo desde mi experiencia, limitándome a algunos puntos a los que el Documento alude.

\section{Planos o niveles}

Quisiera, en primer lugar, señalar los niveles en los que podría darse la ayuda del acompañamiento psicológico en el proceso de Formación.

Son dos los planos en los que puede ayudar

1. En el nivel personal de los seminaristas (con su consentimiento explícito, $\left.n^{\circ} 13\right)$

2. Al equipo de formadores (cuando hablo de equipo, incluyo, obviamente, al rector). Una ayuda o asesoramiento externo, ya 
que el Documento $\left(n^{\circ} 6\right)$ explicita que no puede formar parte del equipo de formadores.

A través de esta comunicación, no será difícil diferenciar los dos planos.

\section{La elección de los psicólogos}

EI Documento de la CEC, habla explícitamente de esto, y creo que es una responsabilidad del equipo de formadores, hacer un serio discernimiento sobre esta elección del psicólogo adecuado para este menester, así como explicitar su papel.

Dice el Documento ( $n^{\circ}$ 6): En la elección de los psicólogos..., además de su madurez humana y espiritual, deben inspirarse en una antropología que comparta abiertamente la concepción cristiana sobre la persona humana, la sexualidad, la vocación al sacerdocio y al celibato..., según la visión de la Iglesia.

Por lo tanto es imprescindible ver qué tipo de psicología maneja el psicólogo.

Existen muchas escuelas de psicología, por lo tanto, muchas formas de interpretar un mismo hecho y muchos tipos de soluciones. Se observa un fenómeno extraño, se diagnostica, se da un planteamiento científico para explicarlo y después se ofrece una terapia acorde con el planteamiento que se ha hecho y la patología existente.

Por lo tanto, el objetivo principal de la psicología, es la descripción de los diversos fenómenos que aquejan al hombre, para sanarlo, para integrarlo. La pregunta será a qué tipo de hombre, cual es la idea de hombre al que quiere ayudar a construir. De ahí que es muy importante para los formadores, al ayudarse de la psicología, conocer cuál es la concepción del hombre en la que está basado el psicólogo. Decíamos que son muchas las escuelas de psicología, y en cada escuela subyace una antropología, sea o no consciente de ella el psicólogo.

No basta con ayudarse de las herramientas que propone una psicología, independientemente de la concepción del hombre que tenga de base. Las herramientas que puedan proporcionar las escuelas de psicología, no son asépticas, llevan implícitas una forma de percibir la realidad y una finalidad objetiva que trasciende a las mismas herramientas (que estarán de acuerdo a la concepción que tenga del hombre).

De ahí la insistencia del Documento en la visión antropológica del psicólogo. 


\section{COMUNICACIÓN \\ El acompañamiento psicológico en el Seminario Mayor}

Además el Documento en el $n^{\circ} 2$, nos da una serie de cualidades, a las que merecen particular atención, que requiere el ministerio sacerdotal.

Las ciencias humanas, como todas las ciencias experimentales, parten de un concepto empírico y estadístico de normalidad. La fe enseña que esta normalidad lleva consigo las huellas de una caída del hombre desde su origen, es decir, está afectada por el pecado. Sólo la fe cristiana enseña al hombre el camino del hombre perfecto (Jesucristo, el santo), un camino que con frecuencia es diverso del de la normalidad empírica y estadística, y es el camino que unifica e integra a la persona en su totalidad. En este sentido, las ciencias humanas, no pueden asumir la función de indicadores de las normas morales. El Evangelio es el que revela la verdad integral sobre el hombre y sobre su camino moral, y le anuncia la misericordia divina, que actúa incesantemente. Además, le recuerda la alegría del perdón, que da la fuerza para reconocer una verdad liberadora, una gracia de esperanza, un camino de vida.

Es decir, por encima de la psicología está la llamada del Señor y la fuerza de la conversión. Sin embargo, muchas veces la persona llamada y con deseo de conversión no tiene las habilidades o la capacidad de poder darse en totalidad, no es libre, algo que sin ser él mismo consciente, le esclaviza $\left(n^{\circ} 5\right)$. En este sentido nos ayudaría la psicología, a descubrir esas esclavitudes, cómo afectan a la persona, a su respuesta vocacional, y a integrarlas. Así la Iglesia, por medio de los formadores, proporciona una integración de la dimensión humana a la luz de la dimensión espiritual, como dice el Documento en el $n^{\circ} 2$.

\section{Relación entre la formación y la psicología}

El Documento, en el $n^{\circ}$ 6, dice: El auxilio de la psicología debe integrarse en el cuadro de la formación global del candidato.

Por eso tenemos que ver la relación entre la Formación y la psicología.

Entre otras, señalo:

+ Existen consonancias, por ejemplo:

- Tienen un objetivo común: El bien de la persona, su integración. La psicología en su nivel ( $\left.n^{\circ} 15\right)$, el formador dándole un eje en el que integrar su totalidad como persona vocacionada, la configuración con Cristo Sacerdote, Cabeza y Pastor.

- Un campo de observación coincidente. La experiencia completa del individuo, y más el formador, que vive diariamente con él.

$+Y$ hay diferencias entre la formación personal y la ayuda psicológica. 
- La perspectiva de la madurez tiene una amplitud diversa (el techo de la psicología es bajo).

- La percepción del campo de observación es diverso. La hermenéutica espiritual y psicológica del fenómeno tiene sus diferencias. Por ej. la desolación, desde el punto de vista espiritual (S. Ignacio) y desde la psicología, la soledad, el afecto, perfecciónsantidad, el aquí y ahora y el kairós, etc.

- La estructura relacional es distinta. La psicología se detiene en la relación entre el terapeuta y el cliente. El formador, y el seminarista, contemplan además la acción del Espíritu, y sin que sean contrapuestas.

\section{La ayuda de la psicología en la formación}

El Documento en el $n^{\circ} 6$, dice que los formadores puedan contar con la colaboración de psicólogos.

¿Qué ayuda puede aportar la psicología a la Formación?

Cuando la Iglesia pide a un formador que acompañe a un candidato en su proceso, le está pidiendo que forme en él la imagen de Cristo. Dicha formación prevé un itinerario hasta llegar al sacerdocio, que el formador tendrá en cuenta, sin olvidar su responsabilidad de discernir la idoneidad y la llamada del candidato al sacerdocio. Saber si tendrá las cualidades, las potencialidades..., necesarias para vivir las exigencias del sacerdocio.

Para el crecimiento y la formación humana (PDV 43), puede valerse de diversos medios que le brinda la psicología. El Documento de la CEC, lo va explicitando, si se hace una lectura atenta, en todo su recorrido. Por mi parte, detallaría algunas:

\section{Puede ayudar a saber 'mirar' $y$ 'escuchar'.}

En la vida diaria con los seminaristas, vemos acontecimientos, gestos, modos, formas..., pero no basta con ver, hay que saber mirar, es decir ver lo que hay detrás, de dónde proceden, qué significan para el individuo, sus coherencias e incoherencias, si va o no acompañada por gestos y de qué tipo, etc., no basta con ver.

Oímos también muchas palabras, que se dicen y nos dicen, pero hay que saber descubrir desde dónde lo dicen, qué significado tiene para la persona, qué sentimientos acompañan, qué quieren decir incluso sus silencios, su forma de expresar, etc. No basta con oír.

Esto ayuda a lograr la empatía y ver el mundo desde la ventana del otro. 


\section{COMUNICACIÓN}

El acompañamiento psicológico en el Seminario Mayor

2. Le ayuda a descubrir la estructura y la dinámica interna de los diversos componentes (consciente, latente, inconsciente) y niveles (físico-social-racional) del yo, con sus consistencias e inconsistencias, etc., de la persona.

- A acoger la lógica interna de las potencialidades y actividades del sujeto (sentimientos, deseos, imaginaciones, decisiones...) en el contexto de un universo subjetivo. Esto lleva al conocimiento de su modo de proceder, la lógica interna de su experiencia.

- A la percepción e importancia de los sentimientos. Por su fuerza (vehemencia, repetición), por su lógica o por carecer de ella, por su coherencia o no (palabras y expresión), etc.

- A ver signos de seguridad o inseguridad, de afectividad oblativa o captativa...

- Descubrir posible rigidez en la personalidad.

- A detectar conductas extrañas.

3 - Ayuda a captar el proceso de maduración de la persona en su devenir

- El proceso de maduración es un continuum. Las escuelas psicológicas van considerado el proceso vital de modo más complexivo, poniendo cada vez más atención a los pasos del crecimiento del individuo.

- De ahí la importancia que tiene la historia de la persona y su proceso, así cómo conocer el ámbito de donde proviene, su contexto cultural, su antes, así como su futuro, el ámbito en el que desarrollará su apostolado, su después.

- El tener en cuenta el proceso evolutivo concreto de la persona.

- Puede aportar conocimientos sobre las motivaciones. Conociéndolas, el formador se dará cuenta de cuáles son las razones por las que el joven quiere seguir el sacerdocio. Aquí la psicología puede ayudar a descubrir motivaciones inconscientes, o latentes, que influyen a la hora de tomar una decisión y evaluar su grado de libertad.

- Además puede señalar dependencias, auto-engaños, compensaciones, huidas de una realidad no asumida...

- A dar pautas para la formación humana (PDV 43, 72) y la maduración afectiva (y su importancia, en PDV 44). 
4.- Ayuda a evitar falsas espiritualizaciones, que pueden complicar la solución del problema, al no querer enfrentar un problema que se da en el plano humano...

\begin{abstract}
5.- Puede ayudar de forma más específica en lo que se refiere a las disposiciones y aptitudes humanas del candidato. Apoyada en el conocimiento multisecular de la Iglesia, la Psicología puede ser un instrumento para conocer signos o señales de algunas patologías que podrían ser un obstáculo, o impedimento, para la vida sacerdotal.
\end{abstract}

Ayuda también a descubrir otras señales de ciertas patologías que, mediante una ayuda adecuada, no impiden el sacerdocio.

Estos síntomas, junto con el análisis que el formador haga, teniendo en cuenta otros aspectos de su personalidad, como pueden ser su formación religiosa, moral, intelectual, etc., pueden ayudar a tomar diversas decisiones sobre la idoneidad de las personas para la vida sacerdotal. Tener muy en cuenta que el desarrollo de la fe permite, también desde el punto de vista psicológico, un pronóstico menos oscuro, y una ayuda psicológica más eficaz, al tener una base profundamente sólida.

De todas formas, para todo esto es recomendable contar con los informes efectuados por un profesional competente, y de sana ciencia psicológica, después de aplicar una batería de tests y varias entrevistas, y tenerlos muy en cuenta.

\title{
5. Los límites de la psicología en la formación
}

La Psicología tiene también sus límites, y quisiera a señalar algunos.

- Por los problemas derivados de algunas psicologías (como ya hemos visto) que interpretan mal el hecho religioso como factor humanizador.

- Los límites de la psicología, dependen de la antropología en la que esté basada (como dijimos). Esto hace, por ejemplo, que sea individualista, centrada en el exclusivo bien del individuo cerrado en sí mismo. La interpretación incorrecta de algunas escuelas del hecho religioso. El permisivismo de una psicología que considera frustrante cada límite puesto por la moral, la ascética, etc.

De una formación de corte excesivamente psicológico, se derivan problemas, como: 


\section{COMUNICACIÓN \\ El acompañamiento en el Seminario Mayor}

- La comprensión del desarrollo de la fe partiendo de las fases antropológicas. Como si el encuentro con Cristo fuera el resultado de un proceso de maduración psicológica.

- El abandono de algunos elementos básicos del crecimiento cristiano: la oración, la ascesis...

- Por algunos esquemas terapéuticos rígidos que tienden a homologar el proceso personal a esquemas pre-establecidos, forzando a la persona a encajar en ellos.

- Por recurrir a interpretaciones psicológicas de algunas enfermedades espirituales..., por ejemplo, desolación-depresión, culpa-culpabilidad, soledad-solitariedad (en PDV 74)...

\section{Un problema importante a abordar hoy, y en el futuro}

El Documento alude varias veces a la identidad sexual, viril dice, del candidato.

La Congregación para la Educación católica, el 4 de noviembre de 2005, publicó una Instrucción Sobre los criterios de discernimiento vocacional concernientes a las personas con tendencias homosexuales en vistas a su admisión al seminario y a las Órdenes Sagradas.

Teniendo muy en cuenta dicha Instrucción, quisiera añadir alguna reflexión al respecto.

Este aspecto es delicado y urgente con respecto al discernimiento de la idoneidad de los candidatos. Se trata de la identidad sexual, de la homosexualidad.

Urgente, por los últimos acontecimientos que en algunas latitudes han saltado con escándalo y que el Papa ha abordado con fuerza y misericordia.

Delicado, por la dificultad de hablar sobre el tema a nivel personal, por parte del formador y más por parte del formando.

No es el momento de hacer un estudio detenido sobre la homosexualidad, y sus diversas formas y diagnósticos, pero es imprescindible encarar estas situaciones con seriedad.

- Por el ambiente creado en la sociedad de hoy por la influencia de la ideología de género y de la cultura gay, más extendida de lo que creemos, por el narcisismo imperante, por los modelos de masculinidad y feminidad que nos ofrecen lo medios de comunicación, etc.. 
- Y por la forma en que la psicología de hoy encara el tema. Por la influencia del lobby gay, en el DSM IV (1995), ya no consta la homosexualidad como una patología, lo cual significa que considera la homosexualidad como algo normal en el hombre y la mujer, y que se evitará en el futuro, que aparezcan baremos en los tests para detectar la presencia posible de tal tendencia.

Sabemos que los tests psicológicos actuales, no son capaces de determinar una homosexualidad precisa y concreta, pero si pueden detectar algún indicio sobre la identidad sexual de la persona y detectar sus probables patologías, como algún tipo de conflicto con la auto-imagen masculina, la orientación de la sexualidad... Esto tenderá a desaparecer en los test e incluso en la consideración de los futuros terapeutas. Esto es muy peligroso, ya que el problema, se puede extender en nuestros ambientes de formación.

Es preciso encararlo con decisión y delicadeza, nunca dejarlo pasar...

La homosexualidad, fuera de la genética, en muchos casos, creo que no es una patología incurable, ya que es más un problema de identidad sexual, pero hay que tomarlo con seriedad, y aceptar el recurso a una terapia psicológica, con el acompañamiento cercano del formador o del director espiritual.

Mi opinión, y según mi experiencia, la terapia necesaria para sanar este tipo de problemas, que la debe hacer un profesional, se tiene que detectar y tratar antes de admitirlo al Seminario. Si se detecta en el proceso de formación, la terapia creo que no se pueden llevar a cabo en el Seminario. Digo esto, porque el ambiente de convivencia próxima, un tanto cerrada y unisexual del seminario, no es el más propicio, como ambiente de apoyo, para una terapia. Además, el discernimiento vocacional, por una parte, y la resolución de la identidad sexual, por otra, tienen suficiente entidad como para captar la atención de toda la persona. Y si el terapeuta no vive en el Seminario, podría tener inconvenientes a la hora de salir para asistir a las entrevistas.

De todas formas, a esta terapia (por parte del profesional) y acompañamiento (por parte del formador - director espiritual), hay que darle tiempo, unos dos años por lo menos (uno de integración y otro de consolidación), dependiendo del proceso. En esto, no hay que tener prisa.

Una vez terminada la terapia, el equipo tendrá que discernir si es llamado por el Señor al sacerdocio o a otro estado de vida.

Muy importante en toda la formación la transparencia y la confianza del candidato con el formador, pero especialmente en esta materia. Para esto, es de gran importancia la actitud de respeto y delicadeza por parte 


\section{COMUNICACIÓN \\ El acompañamiento psicológico en el Seminario Mayor}

del formador; es la manera como el candidato podrá abrirse, sabiendo que en lo que habla, no va a ser juzgado sino acompañado.

Es un aspecto que necesitaría más tiempo para poder profundizarlo y no sólo la consideración de sanar una posible homosexualidad, sino la ayuda a un crecimiento en virilidad, partiendo de una sana aceptación (sin machismo) de esta dimensión constitutiva del que ha nacido varón. El sacerdote célibe como modo de ejercicio de la virilidad, rasgos, modos de crecer en ella; de acompañar... Creo que sería bueno abordar todo esto algún día con más detenimiento.

\section{RESUMIENDO}

La psicología, a pesar de las ayudas que puede dar al formador, nunca podrá sustituir el trabajo que el formador debe realizar. Mientras que el acompañamiento, es un camino en la fe en donde el formador ayuda al joven a responder a la llamada de Dios y discernir su vocación al sacerdocio, el saber psicológico (o el acompañamiento que hemos considerado), le dará luz para conocer, aceptar e integrar el aspecto humano, desde la fe, en la respuesta a su vocación.

No hay que caer ni en un fideísmo ciego, ni en absolutizar la ciencia psicológica, como si fuese una solución a todos los problemas formativos. Ser conscientes, que lo que pueda descubrir a través de la psicología no debe tener un carácter definitivo. De lo contrario, podemos caer en reducir la vocación a una serie de factores humanos, dejando a un lado la acción de la gracia y la libertad del candidato. Puede ser de gran ayuda, pero ni es un recurso omnímodo, ni puede ser el centro del discernimiento. No es de recibo el que un formador diga: el psicólogo dice que fulanito puede ordenarse. No podemos dejar en manos del psicólogo un discernimiento que no corresponde a su papel. Que esto quede claro.

No corresponde al psicólogo dar el OK a las órdenes Este es un discernimiento que corresponde al obispo, bien asesorado por el Rector y su equipo.

La labor del formador puede ayudarse de la psicología, pero no puede nunca ser sustituida por ella, son dos ámbitos diversos, si bien ambos tienden a buscar el bien de la persona. 